(C) 1981. The Genetical Society of Great Britain

\title{
INTER-INDIVIDUAL VARIATION IN CHIASMA DISTRIBUTION IN CHORTHIPPUS BRUNNEUS (ORTHOPTERA: ACRIDIDAE)
}

\author{
D. A. LAURIE* and G. H. JONES \\ Department of Genetics, University of Birmingham, Birmingham B15 2TT
}

Received 15.vi.81

\section{INTRODUCTION}

THERE is little information on the extent of inter-individual variation in chiasma distribution, particularly within natural populations. As this information is clearly important in assessing genetic recombination in natural populations and could also significantly influence our understanding of the regulation of chiasma distribution, we have undertaken a detailed study of inter-individual variation in chiasma distribution in the Common Field Grasshopper, Chorthippus brunneus.

\section{MATERIALS AND METHODS}

Last instar males of Chorthippus brunneus were collected from a natural population on the Birmingham University campus. Testes were dissected into insect saline, fixed in $3: 1$ ethanol/glacial acetic acid and stored at $4^{\circ} \mathrm{C}$. Testis follicles were squashed in 45 per cent acetic acid, the cover-slips removed and the slides placed in absolute ethanol for 5 minutes, and air-dried. Slides were C-banded as follows:

(1) Saturated barium hydroxide at $30^{\circ} \mathrm{C}$ for $3-8$ minutes then wash in running tap water for 30 minutes.

(2) Incubate in $2 \times \mathrm{SSC}$ at $60^{\circ} \mathrm{C}$ for 90 minutes.

(3) Rinse in tap water and stain in 10 per cent Giemsa in $p \mathrm{H} 6.8$ phosphate buffer for 5-10 minutes. Finally rinse in distilled water, dry and mount in D.P.X.

A refinement of the technique was to store slides in $3: 1$ fixative before banding. This improved the reproducibility of the method and allowed the barium hydroxide treatment time to be reduced to 3 minutes.

The Chorthippus brunneus karyotype consists of three pairs of large sub-metacentric chromosomes (L1, L2, and L3), five pairs of smaller telocentric chromosomes (M4, M5, M6, M7 and S8) and a telocentric X chromosome (John and Hewitt, 1966). C-banding reveals constitutive heterochromatin around the centromeres of all chromosomes and at the telomeres of the M7 and S8 chromosomes (Jones et al., 1975). A detailed analysis was made of the single readily identifiable large bivalent, the L3 (fig. 1). L3 bivalents were drawn from projected photographic negatives at a magnification of approximately $\times 2000$, the positions of the centromeres marked and the position of each chiasma measured using a calibrated map measurer. To overcome the problem of variation in absolute bivalent

* Present address: Regional Cytogenetics Laboratory, East Birmingham Hospital, Bordesley Green East, Birmingham B9 5ST. 
length between cells, the position of each chiasma was recorded as the mean distance, averaged over both homologues, from the centromere to the chiasma, expressed as a percentage of the length of the chromosome arm.

Because of the complexity of the chiasma distribution histograms (see fig. 2 and 3), analyses of mean or median values of chiasma position were not considered sufficiently informative. The non-parametric KolmogorovSmirnov test used by Shaw and Knowles (1976) is only applicable to
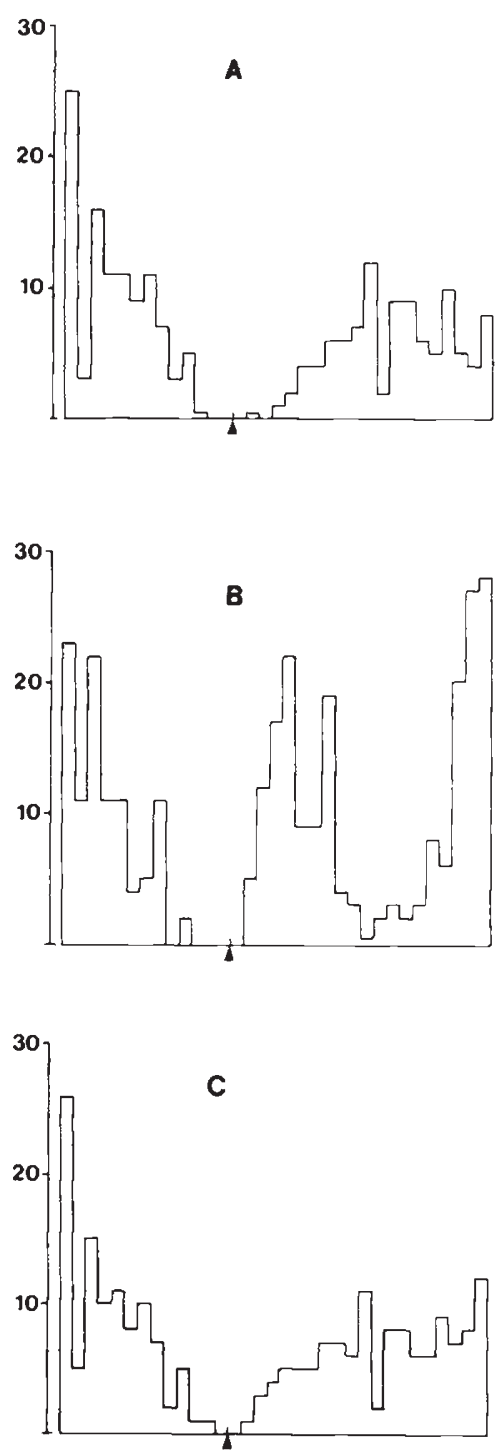

FIG. 2.-The pooled $\mathrm{L}_{3}$ chiasma distribution histogram for 12 males of Chorthippus brunneus. Separate histograms are given for $1: 1$ bivalents (A), $1: 2$ bivalents (B) and all bivalents combined $(C)$, normalised to chiasma frequency per 100 bivalents. Centromere positions are marked by arrows. 


\section{Plate I}

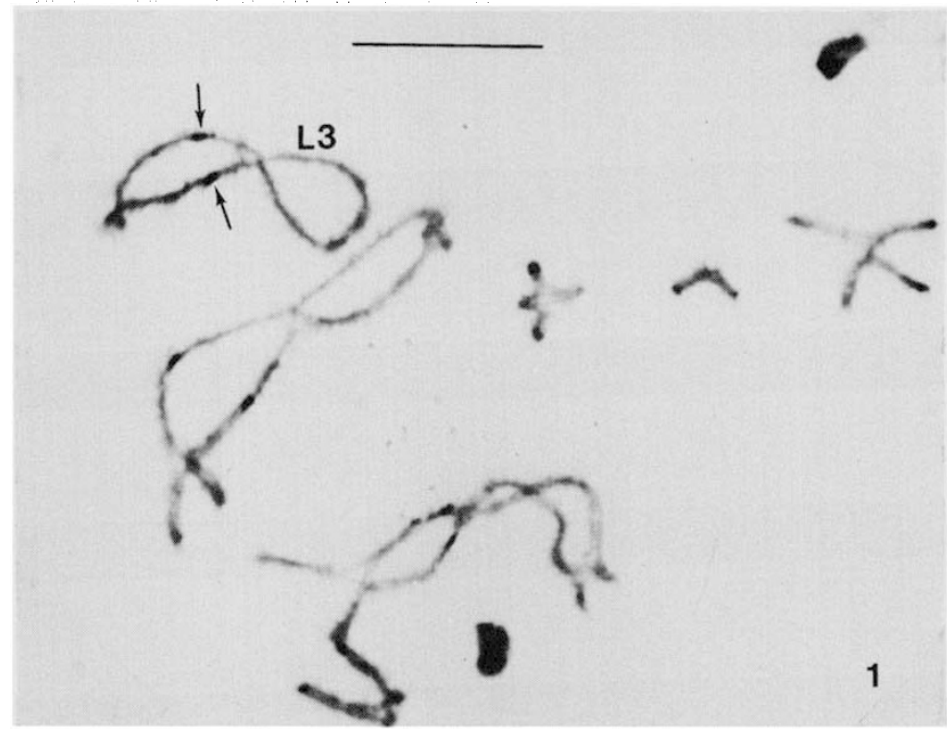

FIG. 1.-A typical C-banded diplotene cell of Chorthippus brunneus of the type used for chiasma analysis, showing the clearly differentiated pericentromeric heterochromatin of the $\mathrm{L}_{3}$ bivalent (arrowed). Bar $=10 \mu$. 

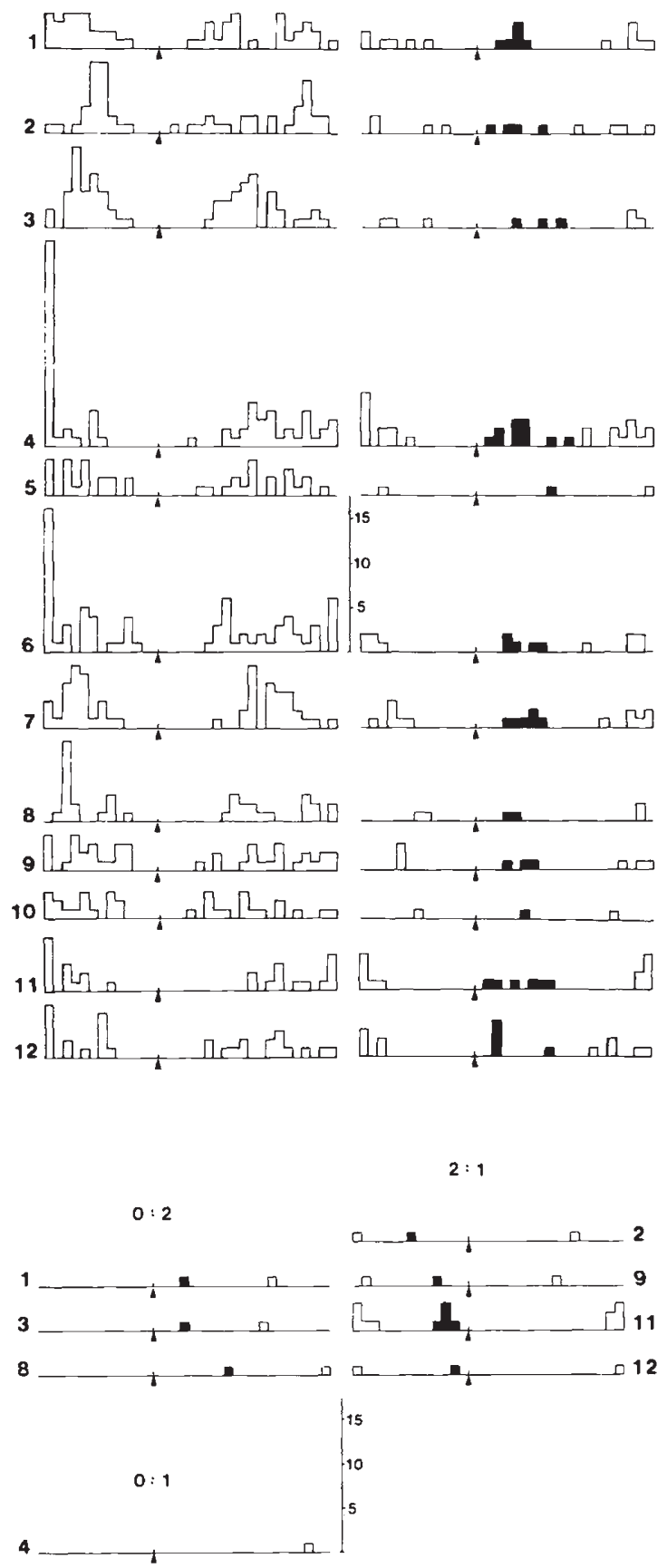

FIG. 3.-Individual $\mathrm{L}_{3}$ chiasma distribution histograms for 12 males of Chorthippus brunneus, showing the different bivalent classes. $(1: 1 ; 1: 2$ etc) separately. Centromere positions are marked by arrows and the more proximal chiasmata in bichisamate arms are represented by solid histogram bars. 
comparisons of pairs of samples and consequently $\mathrm{R} \times \mathrm{C}$ contingency $\chi^{2}$ tests were used to compare the Chorthippus brunneus chiasma distribution histograms (a specimen analysis is shown in table 1). For this test each chromosome arm was divided into a series of intervals which form the columns (C) of the table and the number of chiasmata observed in each interval was entered for each individual, each individual forming a row (R). The expected numbers of chiasmata were calculated for each interval using the marginal totals and the number of bivalents scored for that individual. Initially each bivalent arm was divided into intervals of equal length corresponding to 5 per cent of the long arm, but for the purposes of the $\chi^{2}$ test, the intervals were grouped such that none of the expected values fell below 1 and not more than a third were in the range 1-5 (Lancaster, 1966). The $\chi^{2}$ sum was calculated as $\sum(\mathrm{O}-\mathrm{E})^{2} / \mathrm{E}$ and had $(\mathrm{R}-1)(\mathrm{C}-1)$ degrees of freedom.

\section{RESUltS AND DISCUSSION}

As we are interested in the genetical implications of chiasma distribution, the relationship between the observed positions of chiasmata and the points of crossing-over assumes considerable importance. The movement of chiasmata during meiotic prophase was once considered to be a universal phenomenon (see for example Darlington, 1958) but there are now a growing number of reports which indicate that this is not the case. For example autoradiographic studies of spermatogenesis in Stethophyma grossum (Jones, 1971) and Schistocerca gregaria (Jones, 1977) have produced no evidence of terminalisation and, more recently, studies of the differentially stained bivalents obtained after BrdU incorporation have revealed a precise correspondence between chiasma position and the point of label exchange in Locusta migratoria (Tease, 1978), in male mice (Kanda and Kato, 1980) and probably also in the male Armenian hamster (Allen, 1979) and in female mice (Polani et al., 1979). Preliminary work on Chorthippus brunneus indicates that this precise correspondence also applies to this species (G. H. Jones, unpub. obs.).

\section{(i) Mean chiasma frequencies}

The mean chiasma frequencies of the individual insects studied range from 12.20 to 14.05 chiasmata per cell with a mean for the population sample of 12.97. An analysis of variance shows that the differences between individuals are highly significant $(V R=5.96 ; P<0 \cdot 001)$, in agreement with previous investigations of this species (Hewitt, 1964; Southern, 1967; Westerman, 1971; Maudlin, 1972 and Jones et al., 1975).

The mean L3 bivalent chiasma frequencies of the individual insects range from 2.05 to 2.46 with a mean of 2.16 and an analysis of $\mathrm{L} 3$ bivalent chiasma frequency confirms significant differences between individuals for this metric ( $V R=2 \cdot 14 ; P<0.025)$. L3 bivalents are sub-metacentric with a centromere index of approximately 40 (arm ratio $1: 1 \cdot 5)$. Most bivalents have either one chiasma in each arm or one short arm and two long arm chiasmata. Thus the short arm mean chiasma frequency is usually close to one and increasing mean L 3 chiasma frequencies are the result of increasing proportions of bivalents with two long arm chiasmata. 


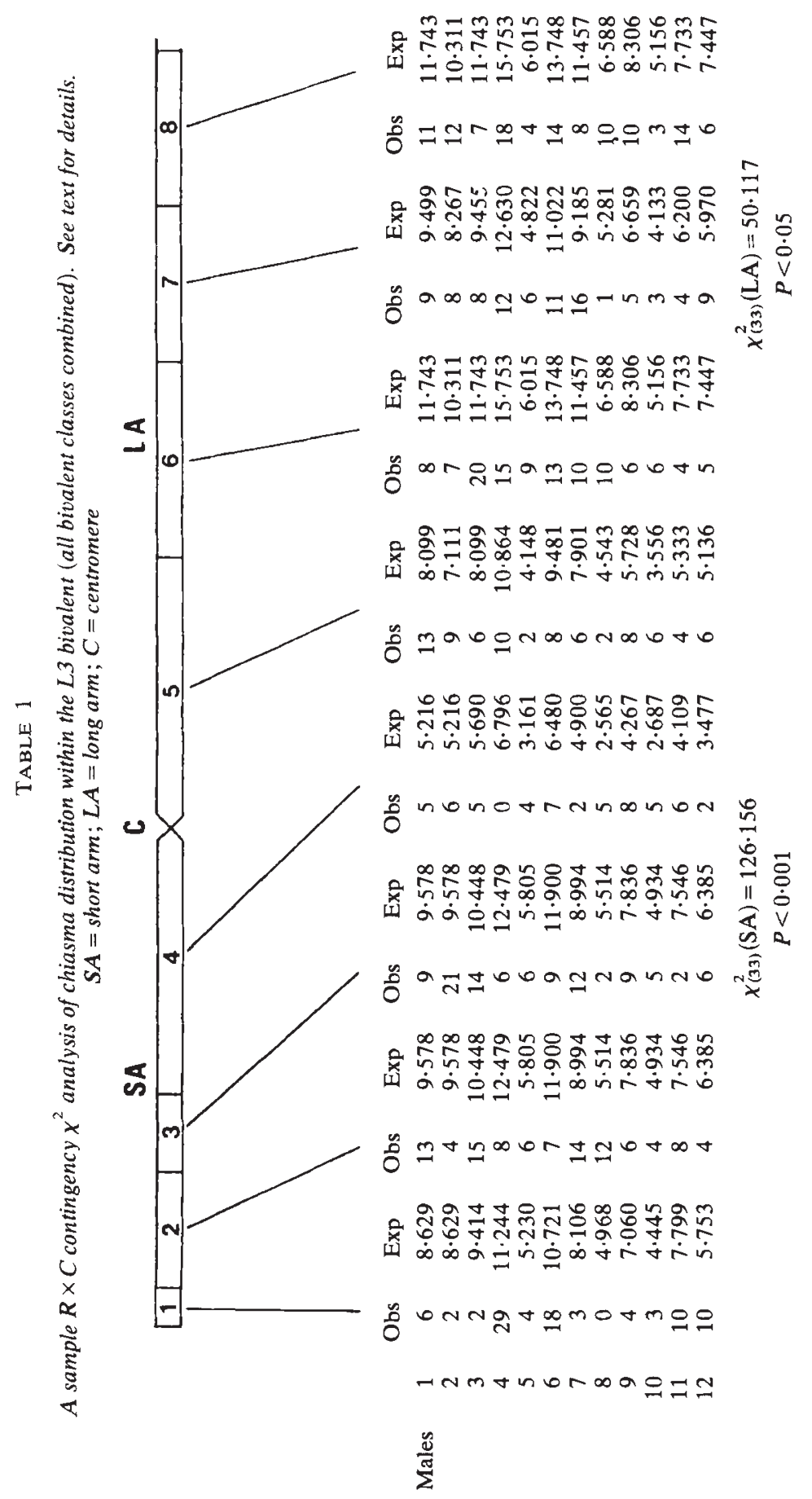




\section{(ii) Chiasma distribution within the L3 bivalent}

Previous detailed studies of chiasma distribution have clearly established that bivalent chiasma frequency and bivalent chiasma distribution are not independent variables (Henderson, 1963; Southern, 1967; Fox, 1973; Hultén, 1974; Shaw and Knowles, 1976 and Maudlin and Evans, 1980); consequently it is necessary to consider bivalents with different numbers of chiasmata separately. These "bivalent classes" are identified in the text by pairs of figures which represent the numbers of short and long arm chiasmata. Thus $1: 1$ bivalents have one chiasma in each arm, $1: 2$ bivalents have one short and two long arm chiasmata and so on.

The numbers of L3 bivalents scored from the 12 insects investigated ranged from 17-45 and the resulting distributions of chiasmata are shown in histogram form in fig. 2 and 3. Figure 2 shows the combined L.3 chiasma distribution histograms for the whole sample of 12 insects, from which the following observations emerge:

(a) The distributions of chiasmata in the long arms of $1: 1$ and $1: 2$ bivalents are quite different. Monochiasmate long arms have a fairly even distribution of chiasmata in the distal two thirds of the arm with a tendency towards an interstitial peak, whereas bichiasmate arms show a distinctly bimodal proximal-distal distribution.

(b) There is a distinct difference between the two arms of $1: 1$ bivalents. In contrast to the broad interstitial-distal distribution of long arm chiasmata, described above, short arm chiasmata are preferentially located distally in several insects, although in some insects interstitial chiasmata predominate in the short arm.

(c) Chiasma formation is rare in the vicinity of the centromere, occurring principally when two chiasmata are formed in one arm. No chiasma was observed which was considered to be located within the heterochromatin of this bivalent.

Figure 3 shows the distribution of chiasmata in the L3 bivalent for each individual, broken down into bivalent classes. The different insects show considerable variability in their chiasma distribution patterns particularly for the short arm. For instance the $1: 1$ bivalent short arm distribution of male 2 with its large interstitial peak and low number of terminal chiasmata contrasts strikingly with those of males 4 and 6 which have large numbers of terminal chiasmata.

The chiasma distributions of all the insects studied were compared using a series of $\mathrm{R} \times \mathrm{C}$ contingency $\chi^{2}$ tests (e.g., table 1 ). The comparisons (table 2) are all significant with one exception. The long arm of the $1: 2$ bivalent could only be divided into two equal intervals because of the small sample size, and the non-significant $\chi^{2}$ obtained is not surprising in view of the strongly bimodal distributions of these arms. These results demonstrate that the males differ significantly not only for mean cell and L3 bivalent chiasma frequencies but also for the distribution of chiasmata within the L3 bivalent. The differences in chiasma distribution do not reflect differences in chiasma frequency since significant differences persist when the analysis is restricted to particular bivalent classes.

Quantitative variations in chiasma distribution within a species have not previously been analysed in detail with the exception of one study by 
TABLE 2

$R \times C$ contingency $\chi^{2}$ comparisons of $L_{3}$ chiasma distribution histograms. Long arm and short arm comparisons are presented separately for all bivalents and 1:1 bivalents. Because of the low numbers of $1: 2$ bivalents, only the long arm gave sufficient data for a comparison

Comparison

Short arm. All bivalents

Long arm. All bivalents

Short arm. 1:1 bivalents only

Long arm. 1:1 bivalents only

Long arm. 1:2 bivalents only

\section{df}

33

33

33

22

5

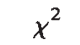

$126 \cdot 16$

$50 \cdot 12$

$114 \cdot 88$

$45 \cdot 38$

$0 \cdot 13$
$P$

$<0.001$

$<0.025$

$<0.001$

$<0.005$

n.s. $(>0.99)$

Shaw and Knowles (1976) who found significant differences in chiasma distribution patterns between populations and races of Caledia species. The present study has shown that there are substantial and significant differences in chiasma distribution between different individual males of Chorthippus brunneus sampled from a natural population (in addition to differences in mean chiasma frequency). It is interesting to compare this situation to that seen in man where a similar quantitative investigation of chiasma distribution in bivalents 1,2 and 9 revealed a marked consistency of chiasma frequency and distribution among seven different men investigated (Laurie et al., 1982). This is interpreted as reflecting a more rigid control over chiasma formation in man resulting in a higher degree of chiasma localisation and less inter-individual variation in chiasma distribution. The implications of the present results for the control of chiasma distribution in Chorthippus brunneus will be discussed more fully in a further paper.

Acknowledgements.-We are grateful to Dr J. S. Gale of this department and Dr P. Davies of the Department of Statistics, University of Birmingham, for valuable advice on the statistical analysis employed. This work was carried out while D.A.L. was in receipt of a Science Research Council C.A.S.E. studentship.

\section{REFERENCES}

ALLEN, J. W. 1979. BrdU dye characterisation of late replication and meiotic recombination in Armenian Hamster germ cells. Chromosoma, 74, 189-207.

DARLINGTON, C. D. 1958. Evolution of genetic systems. 2nd edition. Edinburgh, London: Oliver and Boyd.

FOX, D. P. 1973. The control of chiasma distribution in the locust, Schistocerca gregaria (Forskål). Chromosoma, 43, 289-328.

HENDERSON, S. A. 1963. Chiasma distribution at diplotene in the locust. Heredity, 18, 173-190.

HEWITT, G. M. 1964. Population cytology of British grasshoppers. I. Chiasma variation in Chorthippus brunneus, Chorthippus parallelus and Omocestus viridulus. Chromosoma, $15,212-230$.

HULTÉN, M. 1974. Chiasma distribution at diakinesis in the normal human male. Hereditas, $76,55-78$.

JOHN, B., AND HEWITT, G. M. 1966. Karyotype stability and DNA variability in the Acrididae. Chromosoma, 20, 155-172.

JONES, G. H. 1971. The analysis of exchanges in tritium-labelled meiotic chromosomes. II. Stethophyma grossum. Chromosoma, 34, 367-382. 
JONES, G. H. 1977. A test for early terminalisation of chiasmata in diplotene spermatocytes of Schistocerca gregaria. Chromosoma, 63, 287-294.

JONES, G. H., STAMFORD, W. K., AND PERRY, P. E. 1975. Male and female meiosis in grasshoppers. II. Chorthippus brunneus. Chromosoma, 51, 381-389.

KANDA, N.. AND KATO, H. 1980. Analysis of crossing-over in mouse meiotic celis by BrdU labelling technique. Chromosoma, 78, 113-121.

LANCASTER, H. O. 1966. The chi-squared distribution. New York: John Wiley and Sons, Inc.

LAURIE, D. A., HULTÉN, M., AND JONES, G. H. 1982. Chiasma frequency and distribution in a sample of human males. Chromosomes 1,2 and 9. Cytogenet. Cell Genet. (In Press).

MAUDLIN, I, 1972. Developmental variation of chiasma frequency in Chorthippus brunneus. Heredity, 29, 259-262.

MAUDlin, I., AND EVANS, E. P. 1980. Chiasma distribution in mouse oocytes during diakinesis. Chromosoma, 80, 49-56.

POlANi, P. E., CROllA, J. A., SElleR, M. J., AND MOIR, F. 1979. Meiotic crossing over exchange in the female mouse visualised by BudR substitution. Nature, 278, 348-349.

SHAW, D. D., AND KNOWLES, G. R. 1976. Comparative chiasma analysis using a computerised optical digitiser. Chromosoma, 59, 103-127.

SOUTHERN, D. I. 1967. Chiasma distribution in Truxaline grasshoppers. Chromosoma, 22, 164-191.

TEASE, C. 1978. Cytological detection of crossing-over in BUdR substituted meiotic chromosomes using the fluorescence plus Giemsa technique. Nature, 272, 823-824.

WESTERMAN, M. 1971. The effect of X-irradiation on chiasma frequency in Chorthippus brunneus. Heredity, 27, 83-91. 